\title{
EDITORIAL
}

\section{"NÃO SÃO APENAS NÚMEROS". OLHARES PSICOSSOCIAIS SOBRE MIGRANTES E REFUGIADOS}

\author{
Roberto Marinucci*
}

Não são apenas números! As migrações internacionais, seja quais forem suas causas e efeitos, não podem ser reduzidas a números, a dados estatísticos. Elas são protagonizadas por seres humanos. Não por coletividades abstratas, uniformes e padronizadas - "os" migrantes, "os" estrangeiros, "os" refugiados - e sim por sujeitos concretos que possuem biografias singulares, trajetórias existenciais específicas, recursos materiais, simbólicos e sociais peculiares. O ser humano que sai de sua terra é um ser único e irrepetível, portador de uma identidade moldada no decorrer de sua inédita história, em interação constante com o meio ambiente social, político, econômico e cultural em que viveu (Maalouf, 2009). Olhar as migrações internacionais na ótica psicossocial significa, em outros termos, prestar atenção aos sujeitos, dar prioridade aos atores que as compõem (Martínez, Martínez, 2018). Significa ressaltar a dimensão subjetiva, para além das classificações ligadas a tipologias migratórias, nacionalidade, etnia, religião, classe social e gênero - por vezes necessárias de um ponto de vista burocrático e administrativo, mas, ainda assim, sempre epistemicamente limitadas (Mezzadra, 2015).

$\mathrm{O}$ enfoque psicossocial enxerga o ser humano na sua subjetividade: sua história, seus afetos, suas emoções, seus traumas, suas idiossincrasias, suas esperanças. Não lida com "as" Marias e "os" Abdullá, mas com "esta" Maria e "este" Abdullá. Sujeitos únicos e irrepetíveis, mas que compartilham sua humanidade com todos os demais seres humanos do planeta. O olhar psicossocial mira as continuidades e, ao mesmo tempo, as especificidades da trajetória de cada ser humano em mobilidade. Elucida como seres pertencentes à única humanidade podem trilhar caminhos geográficos e existenciais tão divergentes e diversificados. Caminhos subjetivos de rupturas e reconstruções, de fracassos e conquistas.

Editor-chefe da Revista REMHU, Centro Scalabriniano de Estudos Migratórios (CSEM). Brasília -

DF, Brasil. E-mail: remhu@csem.org.br. Orcid: 0000-0002-2042-2628. 
As migrações internacionais, sobretudo quando marcadas por alguma forma de violência, constituem um âmbito de "mudanças", de reconfigurações identitárias. Não há unanimidade entre os pesquisadores quanto às características e os efeitos dessas mudanças (Beneduce, 2004), pois existe sempre o risco de generalizar experiências específicas e patologizar o ato migratório. Ainda assim, não há dúvida de que a reconstrução do "mundo exterior" é sempre acompanhanda pela necessidade de reconstruir o "mundo interior". Há uma profunda interação entre o simbólico e o material, entre o sujeito e seu meio. No caso específico de migrantes forçados, que fugiram de perseguições e conflitos, o deslocamento geográfico pode garantir a incolumidade física, mas não necessariamente a assim chamada "saúde mental". Sem contar que fatores estressores podem estar presentes e até multiplicar-se na "pacífica" e segura terra de chegada.

Nesses contextos, como desenvolver atividades psicoterapêuticas e de promoção social? De que forma acompanhar os singulares trajetos desses migrantes sem patologizar suas experiências? Como apoiar seus processos de reconfiguração identitária no respeito de suas diferenças culturais? De que maneira oferecer auxílio sem interferir nos tempos e nos espaços da reconstrução interior? Estas e outras perguntas são debatidas no dossiê "Olhares psicossociais sobre migrantes e refugiados" do número 55 da REMHU, Revista Interdisciplinar da Mobilidade Humana. O tema é extremamente desafiador, atual e urgente, pois diz respeito não apenas à ação específica de assistentes sociais, psicoterapeutas e mediadores culturais, mas a todas as práticas de acolhimento e políticas de inclusão. Pode parecer uma obviedade, mas, repetimos, acolher pessoas deslocadas significa lidar com seres humanos, com seus desejos, emoções, afetos, frustrações, traumas, cosmovisões e utopias. Não são apenas números!

No primeiro artigo do Dossiê, Francisco Raga Gimeno desenvolve o tema da comunicação intercultural no âmbito etnopsicoterapeutico a partir de experiências no Senegal. A área da saúde é profundamente desafiada, não apenas pela possível dificuldade da comunicação direta entre o paciente e os profissionais da saúde, mas também, e sobretudo, pela "determinación cultural de las concepciones de la salud mental", tendo em vista que, muitas vezes, há duas diferentes abordagens: a biomédica e a da medicina tradicional. O autor realça como em algumas culturas a raiz da enfermidade mental está fora do doente, em diferentes entes espirituais. Diante disso uma terapia que leve em conta também a cultura dos países de origem dos migrantes deveria contemplar a dimensão espiritual, que é encarnada, por assim dizer, em rituais terapêuticos. O desafio é como pensar um "proceso de hibridación cultural" em que os dois sistemas de cura passam a interagir, envolvendo rituais que atingem tanto a corporeidade quanto o emocional, com a participação não 
apenas do sujeito enfermo e dos profissionais da saúde, mas também da comunidade de origem, enquanto "mediación intercultural comunitária".

Os artigos de Giovanni Giulio Valtolina e Virginia De Micco se debruçam sobre a situação dos menores migrantes. Trata-se de uma realidade específica, pois, nestes casos, as mudanças produzidas pela migração são concomitantes às mudanças psicofísicas. Valtolina aborda a condição dos menores migrantes em sua complexa tarefa de articular os desafios étnicos, referentes à migração, e aqueles do crescimento fisiológico e psicológico, em busca da integração ou do equilíbrio psíquico. O autor aborda várias temáticas, sempre focando a relação do sujeito com o ambiente externo, sobretudo nos âmbitos da família e da educação, num complexo trabalho de construção identititária marcado pelo desejo de diversificação e, ao mesmo tempo, de imitação. Esquematicamente, segundo Valtolina há quatro possíveis caminhos de inclusão no país de chegada: "resistência cultural", "assimilição", "marginalidade" e "dupla etnicidade". Para cada um desses percursos são sinalizados desafios, limites e potencialidades.

Virginia De Micco, por sua vez, enfoca principalmente aqueles casos em que a migração se torna fonte de transtornos identitários e psíquicos e que exigem um profundo processo de reconstrução. Os "adolescentes migrantes" que chegam na Itália devem lidar, por um lado, com os sistemas culturais da terra de origem, que com frequência não respondem aos desafios da terra de chegada, e, por outro, com os sistemas culturais ocidentais, que muitas vezes são apenas superficialmente imitados. Nesse contexto, são frequentes também os desafios da "memória", uma memória que por vezes deve ser apagada ou ofuscada, pois está repleta de histórias impensáveis e indizíveis. É nesse âmbito que o trabalho terapêutico e assistencial busca lidar, de forma paciente e cuidadosa, com esses vazios (buchi) mnemônicos e identitários e suas temporalidades, sabendo "acolher" suas interpelações quando repentinamente as palavras do sofrimento aparecem. O artigo, além de desafios diretamente relacionados ao atendimento psicoterapeutico, levanta também a espinhosa questão daqueles processos burocráticos que exigem um "conto verdadeiro" das jornadas desses migrantes que, na realidade, podem apenas oferecer uma "verità finzionale", que não é uma mentira, e sim um conto paralelo, um conto análogo àquele "impensável" e "indizível".

Os artigos seguintes tratam, de diferentes formas, os desafios do atendimento psicoterapêutico. María Elena Rivera-Heredia, Diana Tamara Martínez-Ruiz, Ericka Ivonne Cervantes-Pacheco, Nydia Obregón-Velasco apresentam os resultados de uma pesquisa de avaliação de um programa de intervenção junto a estudantes de graduação mexicanos que possuem em suas famílias parentes próximos que migraram para o exterior. O objetivo da pesquisa foi identificar o potencial que uma intervenção terapêutica pode 
proporcionar para fortalecer o público-alvo, tanto em termos de potenciação de recursos individuais, sociais e familiares, quanto em termos de redução de sintomas estressores. Os resultados positivos da intervenção atestam a importância da ação psicoterapêutica e podem ser um precioso referencial para políticas públicas e práticas terapêuticas.

Gustavo da Silva Machado, Allyne Fernandes Oliveira Barros e Lucienne Martins Borges refletem sobre a construção de um Serviço de Psicologia dentro de um Centro de Referência de Atendimento a Imigrantes, em Santa Catarina, Brasil, focando, de forma específica, a questão da escuta psicológica e do sofrimento. Os/as autores/as atentam em relação a vários aspectos, como a patologização das diferenças, a naturalização da exclusão, os perigos dos dualismos socioantropológicos e, sobretudo, a relevância da criação de uma rede socioassistencial que abrange os vários recursos que o território oferece. Conforme o texto, um atendimento híbrido entre psicologia clínica e psicologia social requer dos pesquisadores, profissionais e gestores uma ética do deslocamento, um novo olhar para os migrantes e o fenômeno das migrações, que leve em conta todas as dimensões e as dinâmicas biográficas, sociais e culturais dos sujeitos interessados, com vistas à construção de um "lugar" geográfico, social e mental onde "localizar-se".

Antonia Lara também sistematiza uma experiência clínica a partir de um Centro de atendimento na Universidad Católica Silva Henríquez, no Chile. A abordagem da autora está focada na premissa de que os sofrimentos ou mal-estares psíquicos dos migrantes não são necessariamente uma consequência direta do deslocamento. Essa psicopatologização da migração pode chegar "a dar una atribución nacional a la etiología de los síntomas" e ignora que "los síntomas y malestares están vinculados a aquellas condiciones sociales, económicas y políticas en que se despliega el proceso migratorio, y entramadas a una biografía y subjetividad singular". Essa abordagem não visa menosprezar as possíveis experiências violentas e traumaticas decorrentes das travessias, e sim ressaltar como não necessariamente tais experiências desencadeiam psicopatologias, mas podem abrir para processos de subjetivização e reconfiguração identitária.

Os últimos dois artigos do Dossiê se relacionam, de diferentes maneiras, com o envolvimento das Forças Armadas. No primeiro caso, José BerriosRiquelme, Carlos Piñones Rivera e Carla Vidal Figueroa apresentam uma pesquisa sobre asilados chilenos que fugiram para a Suécia durante a ditadura militar de Pinochet. Os autores enfatizam como pessoas com "secuelas físicas y mentales producto de la tortura recibida" tiveram que reconstruir suas vidas no exílio. Com base em entrevistas, são apresentadas as várias etapas do complexo processo de inserção e inclusão na sociedade sueca, um processo marcado por uma dupla passagem: da convicção de um exílio provisório para 
a dificil aceitação de um assentamento duradouro; e, finalmente, após o fim da ditadura, pela passagem do respeitado status de "refugiados" para aquele de meros "imigrantes".

No segundo artigo, a ótica é diferente, pois reflete sobre o envolvimento das Forças Armadas no atendimento e na proteção de populações envolvidas em migrações forçadas, bem como sobre suas implicações psicopatológicas. Hiller Silva Eneterio, Núbia Gonçalves da Paixão Eneterio e Arlete Mendes da Silva apresentam argumentos tanto a favor quanto contra a participação das forças armadas, além de elucidar como violências e outros fatores estressores podem impactar profundamente na saúde psíquica dos solicitantes de refúgio. Cabe destacar a ênfase dada aos sujeitos, ou seja, à percepção que os migrantes têm em relação à presença de forças armadas nas fronteiras: em outros termos, para o migrante que é forçado a entrar irregularmente em outro país a presença de militares na fronteira é um fator estressor ou um fator que gera segurança?

$* * *$

Na seção Artigos Ana Paula Penchaszadeh e Senda Inés Sferco abordam uma temática de extrema relevância no contexto contemporâneo: o assim chamado "crime de solidariedade". A criminalização das migrações e dos migrantes implica, quase que necessariamente, a criminalização de todos aqueles que, de uma forma ou outra, se solidarizam com os recém-chegados. Se no passado ações solidárias eram tidas como "ingênuas", "idealistas" ou "utópicas", hoje se tornaram criminosas por violar as leis migratórias ou por constituir uma deriva "anárquica" e "militante" que desafia a ordem e a segurança nacional. Penchaszadeh e Sferco no artigo em questão abordam o caso do francês Cédric Herrou em sua longa jornada em defesa do direito de socorrer quem está em situação de vulnerabilidade. Após analizar o íter jurídico em seus pormenores, incluindo a decisão do Conselho Institucional francês que, em julho de 2018, em nome do princípio da Fraternidade, "dejó sin efecto la figura del delito de solidaridad", as autoras refletem sobre as categorias analíticas de "hospitalidade" e "solidariedade". Seja como for, a desobediência civil praticada na França, assim como na Itália e em outros países do mundo, revela a existência de princípios e valores que transcendem as legislações nacionais e que constituem fontes de resistência diante das derivas neoliberais e xenófobas.

Jamile Dos Santos Pereira Costa e Maria Catarina Chitolina Zanini analisam as dinâmicas relativas ao processo de reconhecimento da cidadania italiana por parte dos descendentes. As autoras, além de focar as vantagens por assim dizer materiais da obtenção do passaporte - inquestionáveis facilidades nas viagens para o exterior -, atentam principalmente no significado simbólico 
desse documento, tanto como reapropriação afetiva da memória histórica da família e de sua saga, quanto como traço distintivo no solo brasileiro em relação aos não italianos e, inclusive, aos descendentes que não conseguiram a dupla cidadania.

Soraya Ataide, no artigo que encerra a seção, apresenta os resultados de uma pesquisa sobre reprodução de desigulades de gênero entre migrantes bolivianos trabalhadores na produção hortícula na Argentina. A autora enfatiza como, nos casos estudados, essas desiguldades tendem a permanecer, principalmente devido ao fato de que discriminações de classe, nacionalidade e de gênero continuam presentes e marcantes também no lugar de chegada. Além disso, as histórias de algumas mulheres entrevistadas evidenciam como nesse processo há, por vezes, variáveis que em determinadas circunstâncias podem levar à obtenção de maior autonomia, mas que são exceções num contexto familiar e laboral caracterizado pelo patriarcalismo e por uma forte segmentação de gênero.

Na seção Relatos e reflexões, Rosane Costa Rosa apresenta um relato sobre o trabalho desenvolvido pelo Serviço Pastoral dos Migrantes na Arquidiocese de Campo Grande. As diversificadas estratégias de ação, o intenso trabalho em rede e a ação capilar dos voluntários e das voluntárias atestam o compromisso da Pastoral em prol de migrantes e refugiados. As resenhas de Patrícia Nabuco Martuscelli e María de la Luz Martín Carbajal encerram o número da revista.

Desejamos a todas e todos uma boa leitura.

\section{Referências bibliográficas}

BENEDUCE, Roberto. Frontiere dell'identità e della memoria. Milano: Franco Angeli, 2004.

MAALOUF, Amin. L'identità. Milano: Bompiani, 2009.

MARTíNEZ, Manuel Francisco; MARTíNEZ GARCÍA, Julia. Procesos migratorios e intervención psicosocial. Papeles del Psicólogo, v. 39, n. 2, p. 96-103, 2018.

MEZZADRA, Sandro. Multiplicação das fronteiras e das práticas de mobilidade. REMHU, Revista Interdisciplinar da Mobilidade Humana, Brasília, v. 23, n. 44, p. 11-30, Junho 2015. 